\title{
Clinicoepidemiolgic Profile of Dermatophytosis in the Elderly- A Hospital Based Study
}

\author{
Pratik Gahalaut ${ }^{1}$, Mriganka Mehra1, Nitin Mishra1, Madhur Rastogi' ${ }^{1}$, Vasudha Bery ${ }^{1}$ \\ ${ }^{1}$ Department of Dermatology, Venereology and Leprosy, Shri Ram Murti Smarak Institute of Medical Sciences, Bareilly, \\ Uttar Pradesh, India
}

\begin{abstract}
Introduction: Superficial tinea infections are some of the most common dermatological conditions in the elderly. Recently, few studies done showed an abrupt increase in dermatophytic infection in adults; however, similar recent studies describing dermatophytosis in elderly are lacking. The aims and objectives of this study were to identify the epidemiological profile of the dermatophytoses among the elderly population.

Materials and Methods: This was a single centre, observational cross-sectional study conducted at a tertiary care Medical College Hospital in North India over 12 months including patients of dermatophytosis (KOH confirmed) aged 60 years or more.

Results: A total of 192 patients were enrolled, among which $68.7 \%$ were males. Extensive disease was present in $56.2 \%$. History of topical steroid usage was present in $79.2 \%$. Mean duration of disease was 23.8 weeks among which chronic disease was seen in $25 \%$. Various other demographic characteristics were identified. Various risk factors for extensive disease, like gender, topical steroids use, urban residence, higher socioeconomic status, longer duration of disease, positive family history, diabetics, regular alcohol and tobacco consumption, were also noted in present study.

Conclusion: The present concludes increased prevalence in women, delay in seeking treatment among them, rising proportion of chronic and extensive dermatophytosis, rising atypical clinical presentation and higher predilection for tinea cruris and onychomycosis.
\end{abstract}

Key words: Dermatophytosis; Epidemiology; Geriatric

\section{Introduction}

1 The 'National Policy on Older Persons' of Government of India describes an 'Elderly' as a person who is 60 years of age or above. ${ }^{1}$ Population ageing is a dynamic phenomenon, which is seen all around the world, leading to an increase in the number of elderly. ${ }^{2}$ There has also been a marked increase in dermatophyte infections in India in the past few years. $^{3,4}$

Funding: No

Conflict of Interest: No

\section{Address of Correspondence}

Dr. Mriganka Mehra, MBBS

ORCID ID- 0000-0003-4601-9471

Department of Dermatology, Venereology and Leprosy, Shri Ram Murti Smarak Institute of Medical Sciences, Bareilly, Uttar Pradesh, India

Tel: +9170420 207558, +919458708853

E-mail: mrigankamehra1@gmail.com
Consequently, the number of geriatric persons afflicted with dermatophytosis is bound to go up. This is further complicated by the rampant and irrational use of over the counter topical steroidal preparations. In the Indian context, use of topical steroids-antifungal combination creams contribute to the ever-increasing numbers of chronic and recalcitrant dermatophytosis seen in our country. ${ }^{4,5}$

Date of Submission: $1^{\text {st }}$ July 2021

Date of Acceptance: $26^{\text {th }}$ August 2021

Date of Publication: $1^{\text {st }}$ October 2021

How to cite this article

Gahalaut P, Mehra M, Mishra N, Rastogi M, Bery V. Clinicoepidemiolgic profile of dermatophytosis in the elderlyA hospital based study. NJDVL 2021;19(2):26-33. https://doi. org/10.3126/njdvl.v19i2.38496.

\section{(i)}

Licensed under CC BY 4.0 International License which permits use, distribution and reproduction in any medium, provided the original work is properly cited. 
Despite the expanding scale of this grave problem, we do not have any literature exploring dermatophytosis in the older patients. The aim of this study is to familiarize ourselves with the demographic and clinical characteristics of the elderly presenting with dermatophytic infections, and relating these characteristics to extent of disease as well as topical steroid use.

\section{Materials and Methods}

This was a single center, observational cross-sectional study conducted at a tertiary care medical college hospital in North India over 12 months- December 2018 to November 2019. Written informed consent was obtained from all participants. Due permission from the institutional ethics committee was obtained.

\section{Patient Selection}

Consecutive patients, aged 60 years or more, who were clinically diagnosed with dermatophytosis and were $\mathrm{KOH}$ positive were included. $\mathrm{KOH}$ mount was done from the primary site (site with largest lesion). Patients unwilling to participate, be examined or undergo investigations and those taking systemic steroids or immunosuppressants were excluded. Patients having any concurrent dermatological disorder were also excluded.

\section{Study Protocol and Outcomes}

All patients were subjected to thorough history taking, clinical examination and Potassium hydroxide mount examination. Data regarding basic demographic characters, complaints, family history, cutaneous examination, treatment history and other relevant details were noted in a pre-designed form. Patients were sub-divided based on various characteristics. A single site involvement was considered as localized disease while more than one site was considered extensive disease. Data thus obtained was collected and tabulated. For statistical analysis of the data, SPSS (Statistical Package for the Social Sciences) Software was used. Chi-square test was applied for comparison between variables. The results were considered significant at $P$-value $<0.05$.

\section{Results}

Among a total of 25,000 patients presenting to the Dermatology Out Patient Department during the span of our study, 2025 (8.1\%) patients were elderly. Among the 2025 elderly patients, 192 (9.5\%) met with the inclusion criteria of our study.

Single site involvement or localized disease was seen in a total of 84 patients (43.8\%) whereas extensive disease was seen in 108 patients (56.2\%). History of topical steroid usage was present in a total of 152 out of the 192 study patients (79.2\%).

With regard to gender distribution, 132 were males (68.75\%) and 60 were females (31.25\%). It was found that the females had significantly higher likelihood of presentation with extensive disease $(p=0.007)$ and lesser usage of topical steroids prior to presentation. $(p<0.001$, Table 1$)$

Mean duration of disease was found to be $33.6 \pm 17.3$ weeks with a range of 2-64 weeks, out of which majority (75.0\%) of the patients presented with 6 months or less duration, while chronic dermatophytosis (> 6 months) was seen in $25 \%$. The persons with chronic disease had a significantly higher tendency to use topical steroids $(p<0.001)$, and to present with extensive disease. $(p<0.001$, Table 1$)$

Mean age of presentation was $66.2 \pm 6.6$ years with a range of $60-85$ years. Majority of the patients belonged to the $60-69$ years group. A significantly higher portion of this age group presented with extensive disease $(p<0.001)$, when compared to patients aged 70 years and older. Among the 70 years and older group, a significantly higher percentage $(93.7 \%)$ had a history of topical steroid usage $(p=0.009$, Table 1$)$. Only 4 patients were 80 years of age or older.

According to Revised Modified B.G. Prasad Scale Socioeconomic classification scale 2017, majority patients were from Lower class $(41.6 \%)$, followed by Lower Middle (27\%). Least number of patients belonged to Middle Class (6.2\%). Patients with higher socioeconomic status were significantly more likely to use topical steroids $(p<0.001)$ and present with extensive disease. $(p<0.001$, Table 1$)$

With regard to occupation, majority of participants were unemployed (33.3\%), followed by $27 \%$ farmers. More than half of the patients hailed from rural areas (64.5\%) and rest from urban residential areas. Out of these $(3.6 \%)$ were from urban slum region. Persons hailing from urban residences were more likely to use topical steroidal preparations $(p=0.248)$ and to present with extensive disease. $(p=0.051$, Table 1$)$

Furthermore, a positive family history of fungal infections was found in 112/192 patients (58.3\%). Persons with other family members suffering from dermatophytosis were significantly more likely to present with extensive disease and use topical steroids. $(p<0.001$, Table 1) 
Out of the 192 subjects, 80 had a history of regular tobacco consumption in some form whereas 28 had history of regular alcohol consumption. Among the former group, 52 persons (65\%) had extensive disease while in the latter, $57.1 \%$ were found to have more than one site involvement. The persons with history of tobacco usage and regular alcohol consumption were significantly more likely to present with extensive disease $(p<0.001$, Table 1$)$

Among 192 patients, $79.2 \%$ had a history of steroid use. Among the group with extensive disease, $85.1 \%$ patients had a history of topical steroid use while among those with localized disease, $71.4 \%$ had such history. While the mean duration of topical steroid use among all patients was $5.6 \pm 2.8$ weeks, it was7.2 \pm 2.2 weeks and $3.2 \pm 1.6$ weeks in the extensive and localized groups respectively. (Table 2 )

Commonest complaints were redness and rash in $83.3 \%$ followed by itching and flaking in $72.9 \%$. Other presenting complaints included discoloration, burning and oozing. (Table 3)

Systemic ailments were noted in 115 patients, among which few had more than one condition. Commonest systemic ailment was Diabetes Mellitus seen in 40 (20.8\%), followed by Hypertension in 36 (18.7\%), Coronary artery disease in 15 (7.8\%). Other illnesses were all less than $5 \%$. (Table 4). A total of $60 \%$ among the diabetics presented with extensive disease.

Table 5 describes the site wise distribution of disease. The commonest site to be affected was groin in $41.6 \%$ followed by trunk in $39.5 \%$. Lesions over face and onychomycosis were seen in $14.5 \%$ patients each. (Figures 1, 2). Single site involvement or localized disease was seen in 84 patients $(43.8 \%)$ whereas extensive disease was seen in 108 patients (56.2\%). Mean body surface area involved was $7.0 \pm 5.9 \%$ with involvement ranging between $1-30 \%$.

Table 1: Various Demographic Factors And Their Association With Steroid Use And Extensive Disease

\begin{tabular}{|c|c|c|c|c|c|c|}
\hline \multirow{2}{*}{$\begin{array}{l}\text { Gender } \\
\text { Male }\end{array}$} & \multirow{2}{*}{$\begin{array}{c}\begin{array}{c}\text { Number } \\
\mathbf{n}=192 \\
132\end{array} \\
\end{array}$} & \multirow{2}{*}{$\begin{array}{c}\text { Percentage } \\
(\%)\end{array}$} & \multicolumn{2}{|c|}{$\begin{array}{l}\text { Percentage (\%) among each } \\
\text { group with extensive disease }\end{array}$} & \multicolumn{2}{|c|}{$\begin{array}{l}\text { Percentage (\%) among each } \\
\text { group with steroid use }\end{array}$} \\
\hline & & & 51.5 & \multirow{2}{*}{$p=0.007$} & 84.8 & \multirow{2}{*}{$p<0.001$} \\
\hline Female & 60 & 31.2 & 66.6 & & 66.6 & \\
\hline \multicolumn{7}{|c|}{ Duration (months) } \\
\hline$\leq 6$ months & 144 & 75.0 & 44.4 & \multirow{2}{*}{$p<0.001$} & 75.0 & \multirow{2}{*}{$p<0.001$} \\
\hline$>6$ months & 48 & 25.0 & 91.6 & & 91.6 & \\
\hline \multicolumn{7}{|c|}{ Age group (in years) } \\
\hline $60-69$ & 128 & 66.7 & 59.3 & \multirow{2}{*}{$p<0.001$} & 71.8 & \multirow{2}{*}{$p=0.009$} \\
\hline$\geq 70$ & 64 & 33.3 & 50.0 & & 93.7 & \\
\hline \multicolumn{7}{|c|}{ Socio economic Status } \\
\hline Lower & 80 & 41.6 & 60.0 & \multirow{5}{*}{$p<0.001$} & 75.0 & \multirow{5}{*}{$p<0.001$} \\
\hline Lower Middle & 52 & 27.0 & 38.4 & & 61.5 & \\
\hline Middle & 12 & 6.2 & 33.3 & & 100 & \\
\hline Upper Middle & 24 & 12.5 & 66.6 & & 100 & \\
\hline Upper & 24 & 12.5 & 83.3 & & 100 & \\
\hline \multicolumn{7}{|l|}{ Residence } \\
\hline Rural & 124 & 64.5 & 48.3 & \multirow{2}{*}{$p=0.051$} & 70.9 & \multirow{2}{*}{$p=0.248$} \\
\hline Urban & 68 & 35.5 & 70.5 & & 94.1 & \\
\hline \multicolumn{7}{|l|}{ Family History } \\
\hline Present & 112 & 58.3 & 71.4 & \multirow[b]{2}{*}{$p<0.001$} & 78.5 & \multirow{2}{*}{$p<0.001$} \\
\hline Absent & 80 & 41.7 & 35.0 & & 20.0 & \\
\hline \multicolumn{7}{|l|}{ Addictions } \\
\hline Tobacco & 80 & 41.6 & 65.0 & \multirow{2}{*}{$p<0.001$} & 80.0 & \multirow{2}{*}{$p<0.001$} \\
\hline Alcohol & 28 & 14.5 & 57.1 & & 57.1 & \\
\hline
\end{tabular}

Table 2: Comparison Of Topical Steroid Use And Extent Of Disease

\begin{tabular}{|l|c|c|}
\hline Topical steroid use & Localized disease $(\mathbf{n = 8 4})$ & Extensive disease $(\mathbf{n = 1 0 8 )}$ \\
\hline History (\%) & 71.4 & 85.1 \\
\hline Mean duration of use (weeks) & 3.2 & 7.2 \\
\hline
\end{tabular}


Table 3: Presenting Complaints

\begin{tabular}{|l|c|c|}
\hline Complaints & Number $(\mathbf{n = 1 9 2 )}$ & Percentage (\%) \\
\hline Rash & 160 & 83.3 \\
\hline Redness & 152 & 79.1 \\
\hline Flaking & 140 & 72.9 \\
\hline Itching & 140 & 72.9 \\
\hline Discoloration & 20 & 10.4 \\
\hline Burning & 4 & 2.0 \\
\hline Oozing & 4 & 2.0 \\
\hline Pus filled lesions & 4 & 2.0 \\
\hline
\end{tabular}

Table 4: Systemic Illnesses

\begin{tabular}{|l|c|c|}
\hline Systemic Diseases & Number $(\mathbf{n = 1 9 2 )}$ & Percentage (\%) \\
\hline Diabetes Mellitus & 40 & 20.8 \\
\hline Hypertension & 36 & 18.7 \\
\hline Coronary Artery Disease & 15 & 7.8 \\
\hline Kidney Disease & 6 & 3.1 \\
\hline Malignancy & 6 & 3.1 \\
\hline COPD & 5 & 2.6 \\
\hline Tuberculosis & 4 & 2.0 \\
\hline Chronic liver disease & 3 & 1.5 \\
\hline
\end{tabular}

Table 5: Primary Sites Involved

\begin{tabular}{|l|c|c|}
\hline Sites & Number $(\mathbf{n = 1 9 2 )}$ & Percentage (\%) \\
\hline Groin & 80 & 41.6 \\
\hline Trunk & 76 & 39.5 \\
\hline Legs & 48 & 25.0 \\
\hline Buttocks & 32 & 16.6 \\
\hline Face \& Neck & 28 & 14.5 \\
\hline Nails & 28 & 14.5 \\
\hline Arms & 12 & 6.2 \\
\hline Hands & 12 & 6.2 \\
\hline Feet & 12 & 6.2 \\
\hline
\end{tabular}

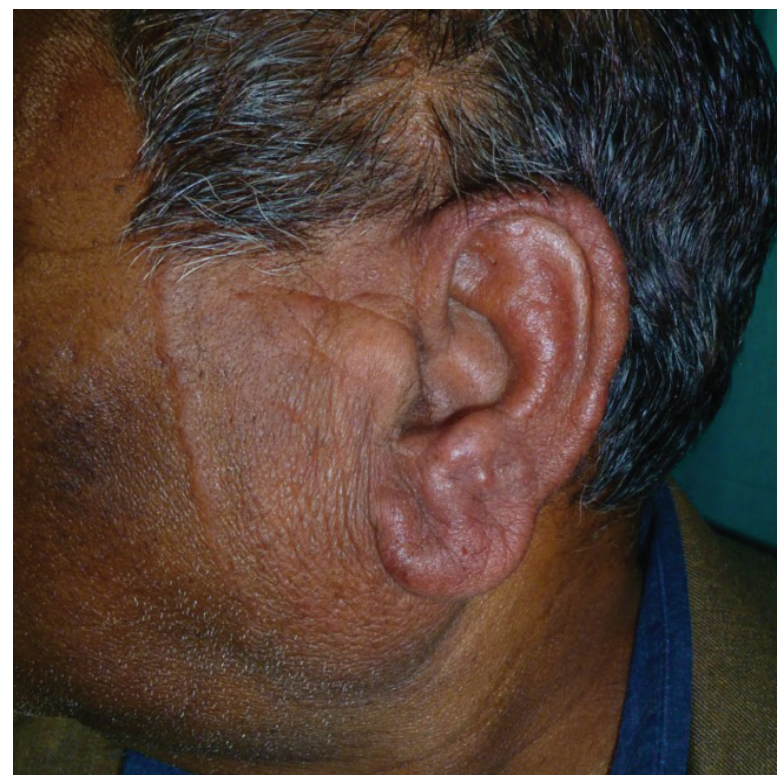

Figure 1: Tinea faciei Annular erythematous plaque over face extending to ear

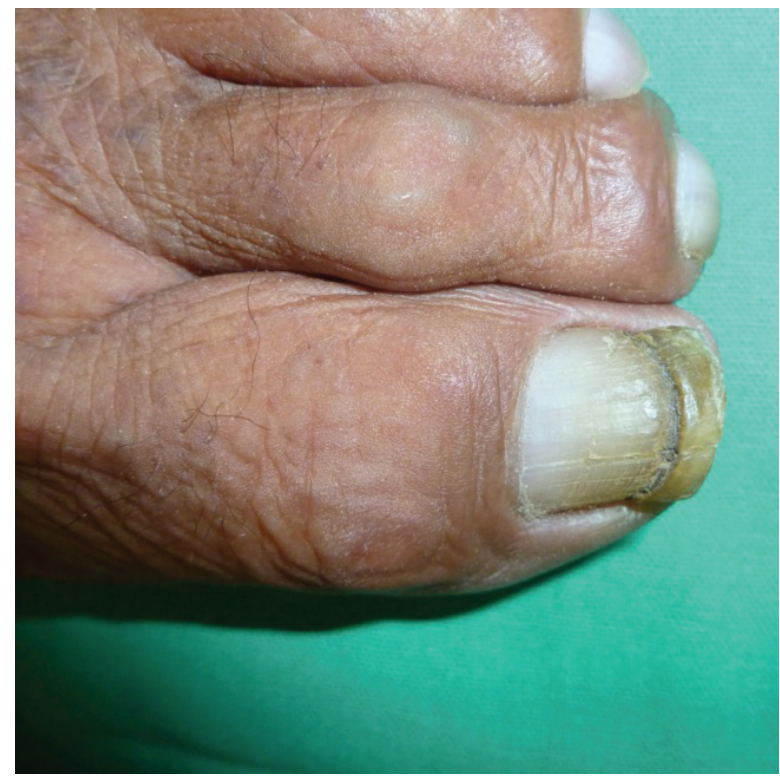

Figure 2: Onychomycosis affecting toenail- (Distal Lateral Subungal type) 


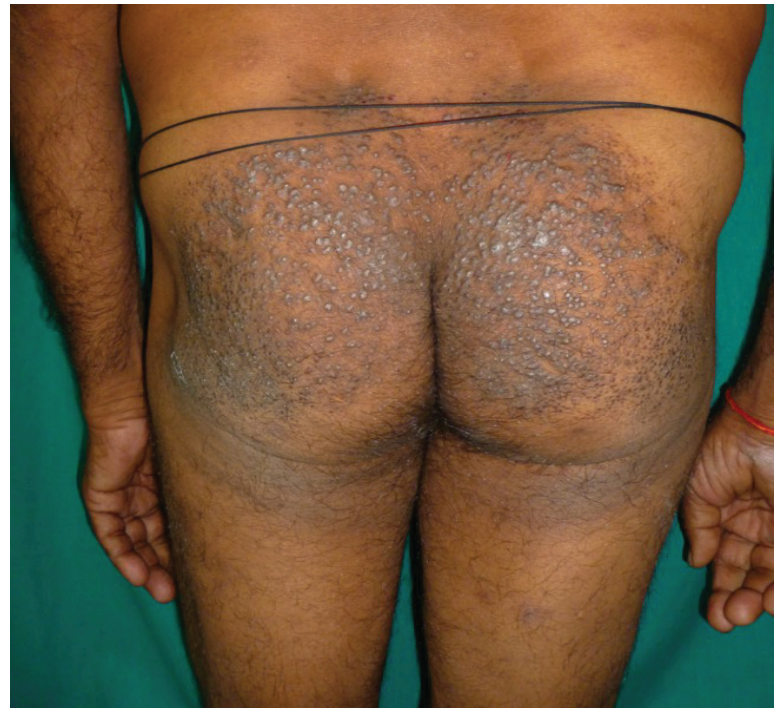

Figure 3: Atypical Presentation of dermatophytosisLichenified plaques as a result of long standing disease and prolonged topical steroid use

\section{Discussion}

Many studies have been conducted on superficial dermatophytosis in the recent times, however not much data is available with regard to the elderly population. . $^{67}$ It is essential to study the demographic pattern of this ever-increasing disease in the elderly to provide optimum care, both pharmacological and non-pharmacological. An understanding of the demographic characteristic of this special population aids us in advising measures for effective management, preventing spread and tackling chronic, recurrent or recalcitrant disease. It empowers us to educate the afflicted patients in better manner. ${ }^{8}$ This discussion aims to contrast and compare the results of our study with earlier studies in the adult population and where available, data from the elderly population.

The male to female ratio in our study was $2.2: 1$, which corroborates the recent trend of rising prevalence in women. ${ }^{9,10}$ This is in contrast to the older studies where a higher male to female ratio was seen (3-5:1). ${ }^{7,11}$ It was conventionally believed that men are more likely to be affected and have more extensive disease, due to various factors like greater outdoor work in warm and sweaty conditions. However, as reflected in our study as well, this difference in occurrence of dermatophytosis between the genders is starting to reduce. ${ }^{7}$

While older studies show the prevalence of chronic dermatophytosis to be around $10 \%$ more recent studies show a prevalence as high as $68 \%$ among adults. ${ }^{12}$ In the elderly, we found that chronic dermatophytosis was

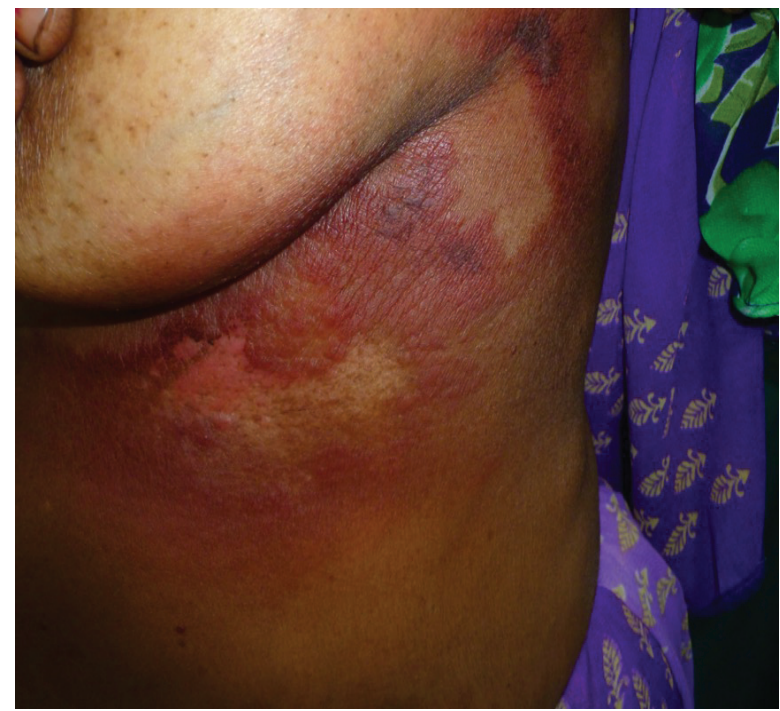

Figure 4: Atypical presentation of dermatophytosisBrightly erythematous plaques with erosions as due to use of cocktail of over the counter topicals.

seen in $25 \%$ patients. As high as $91 \%$ patients suffering from chronic dermatophytosis had a history of topical steroid use. This goes to reiterate our understanding that topical steroids profoundly suppress cutaneous inflammatory responses, allowing the organism to proliferate unchecked. This ultimately leads to the chronicity of disease. ${ }^{13}$

Majority of our patients belonged to the 60-69 years age group, but we found that patients 70 years or older had a greater tendency to self-medicate with topical steroids prior to presentation. This could possibly be explained by a delay in seeking proper medical help for the older patients due to neglect or difficulty in travelling. In the interim, they find temporary symptomatic relief with the widely available combination creams containing steroids. However, such a finding has not been documented in previous literature.

Majority of the patients in our study belonged to the lower socioeconomic strata as has been seen in previous studies. This is expected due to factors like poor hygiene, crowding and lower awareness. ${ }^{14}$ However, the use of topical steroid and consequently presentation with extensive disease was much more in the higher socioeconomic strata. This is likely to stem from the easy over- the-counter availability of irrational drug combinations of potent topical steroids. The same reasoning also goes to explain our finding of greater tendency of patients hailing from urban residences to self-medicate with topical steroids. ${ }^{15}$ 
A higher percentage of our patients were from Rural areas which is in contrast to an older study. ${ }^{14}$ This is explained by the location of our tertiary centre and the fact that it caters to a large number of villages.

Familial contacts were found in as high as $58.3 \%$. Family history in older studies in adults ranges from $20-48 \%,{ }^{16,17}$ but in children was as high as $90 \%{ }^{18}$ Special populations like elderly and children have relatively lesser contact with persons outside their family hence they are more likely to be infected by a family member. Various factors at play in the Indian scenario are overcrowding, poor hygiene, sharing of clothes, towels, linen and footwear. ${ }^{19,20}$

We also found a higher propensity for steroid use and extensive disease in patients with positive familial contacts. We theorize that the likelihood of using topical combination creams increases when a family member, for the temporary symptomatic relief they provide, recommends them to other familial contacts. It has been noted in a previous study that there is a tendency among all affected family members to misuse topical steroids. ${ }^{21}$

A high percentage (42-81\%) of dermatophytosis patients nowadays present with prior self-medication with topical steroids or combination creams. ${ }^{20,21}$ Among our subjects, this history was found to be present in $79.1 \%$. This was much higher in those with extensive disease $(85.1 \%)$ with a mean duration of use being higher than those with localized disease. This goes to show that topical steroids are a major contributor to the menace of chronic, extensive dermatophytosis among the elderly too, as with other age groups. ${ }^{4}$

Majority of the patients presented with complaints of a rash however many had atypical presentations too, like lack of erythema, lack of itching, burning, oozing, discolouration of skin and pus-filled lesions. (Figures 3,4) These are all consequences of steroid modified forms of dermatophytosis and have been well documented in previous studies in adults. ${ }^{7}$

Commonest systemic ailment in the elderly was Diabetes mellitus in our study (20.8\%), which is comparable to previous studies in the adult population. ${ }^{16}$ As one would expect, a markedly high proportion of diabetics also had extensive disease. A number of patients, among the study population, also suffered from hypertension and cardiac disease. In these patients, with co-morbidities and polypharmacy, the treating doctor has to bear in mind the various drug interactions and side effects of oral antifungal agents.

A high proportion of tobacco chewers, smokers and regular alcohol drinkers also presented with extensive disease. These are the previously established risk factors for chronic recalcitrant disease in adults, and our findings in the elderly reflect the same..$^{22}$

In our study, multiple site involvement was seen in $56.2 \%$ which is higher than previous studies in adult population. ${ }^{16,23}$ Tinea cruris was found to be the commonest form followed by Tinea corporis. This differs from previous studies in adults where Tinea corporis is the commonest form. ${ }^{16,24} \mathrm{~A}$ higher prevalence $(20 \%)$ of onychomycosis is documented in the elderly in the past, compared to an overall lower prevalence (10-13\%). ${ }^{16,24}$ In our study it was found to be $14.5 \%$. This higher prevalence in the elderly is due to ageing related changes in the nails like biomechanical alterations, impaired blood supply, trauma and reduced immunity. ${ }^{25}$

Limitations of our study were that it was a single center, hospital based study.

\section{Conclusion}

The present study brings to light various epidemiological trends in elderly dermatophytosis like increased prevalence in women, delay in seeking treatment among them, rising proportion of chronic and extensive dermatophytosis, rising atypical clinical presentation, higher predilection for tinea cruris and onychomycosis. It also highlights the various risk factors for extensive disease in elderly like- female gender, topical steroid use, urban residence, higher socioeconomic status, longer duration of disease, positive family history, diabetics, regular alcohol and tobacco consumption. 


\section{References}

1. Statistics E. Central statistics office, Ministry of Statistics and Programme Implementation. Govt. of India, New Delhi (22nd Issue)(www. mospi. gov. in). 2015.

2. Ingle GK, Nath A. Geriatric health in India: Concerns and solutions. Indian J Comm Med: official publication of Indian Association of Preventive \& Social Medicine. 2008 Oct;33(4):214. https://doi. org/10.4103/0970-0218.43225

3. Bishnoi A, Vinay K, Dogra S. Emergence of recalcitrant dermatophytosis in India. Lancet Infect Dis. 2018 Mar 1;18(3):250-1. https://doi. org/10.1016/S1473-3099(18)30079-3

4. Verma SB, Zouboulis C. Indian irrational skin creams and steroid-modified dermatophytosis-an unholy nexus and alarming situation. J Eur Acad Dermatol Venereol. 2018 May 24;32(11):e426-7. https://doi.org/10.1111/jdv.15025

5. Verma SB. Sales, status, prescriptions and regulatory problems with topical steroids in India. Indian J Dermatol Venereol Leprol. 2014 May 1;80(3):201. https://doi.org/10.4103/03786323.132246

6. Lakshmanan A, Ganeshkumar P, Mohan SR, Hemamalini M, Madhavan R. Epidemiological and clinical pattern of dermatomycoses in rural India. Indian J Med Microbiol. 2015 Feb 1;33:S134-6. https://doi.org/10.4103/0255-0857.150922

7. Verma $S B$, Panda $S$, Nenoff $P$, Singal $A$, Rudramurthy SM, Uhrlass S, Das A, Bisherwal K, Shaw D, Vasani $R$. The unprecedented epidemic-like scenario of dermatophytosis in India: I. Epidemiology, risk factors and clinical features. Indian J Dermatol Venereol Leprol. 2021 Mar 1;87(2). https://doi. org/10.25259/IJDVL_301_20

8. Kaul S, Yadav S, Dogra S. Treatment of dermatophytosis in elderly, children, and pregnant women. Indian Dermatol Online J. 2017 Sep;8(5):310. https://doi.org/10.4103/idoj. IDOJ_169_17

9. Pathania S, Rudramurthy SM, Narang T, Saikia UN, Dogra S. A prospective study of the epidemiological and clinical patterns of recurrent dermatophytosis at a tertiary care hospital in India. Indian J Dermatol Venereol Leprol. 2018 Nov 1;84(6). https://doi.org/10.4103/ijdvl. IJDVL_645_17

10. Vineetha $M$, Sheeja $S$, Celine $M I$, Sadeep MS, Palackal S, Shanimole PE, Das SS. Profile of dermatophytosis in a tertiary care center. Indian
J Dermatol. 2018 Nov;63(6):490. https://doi. org/10.4103/ijd.IJD_177_18

11. Bhatia VK, Sharma PC. Epidemiological studies on dermatophytosis in human patients in Himachal Pradesh, India. Springerplus. 2014 Dec;3(1):1-7. https://doi.org/10.1186/2193-1801-3-134

12. Sentamilselvi G, Kamalam A, Ajithadas K, Janaki C, Thambiah AS. Scenario of chronic dermatophytosis: An Indian study. Mycopathologia. 1997 Dec;140(3):129-35. https://doi.org/10.1023/A:1006843418759

13. Vineetha M, Sheeja S, Celine MI, Sadeep MS, Palackal S, Shanimole PE, Das SS. Profile of dermatophytosis in a tertiary care center. Indian J Dermatol. 2018 Nov;63(6):490. https://doi. org/10.4103/ijd.IJD_177_18

14. Janardhan B, Vani G. Clinico mycological study of dermatophytosis. Int J Res Med Sci. 2017 Jan;5(1):31-9. http://dx.doi. org/10.18203/2320-6012.ijrms20164399

15. Thakur R, Kalsi AS, Kushwaha $P$, Singh $P$. Epidemiology of cortico-steroid-modified tinea: study of 100 cases in a rural tertiary care teaching hospital of Western Uttar Pradesh, India. J Dermat Cosmetol. 2018;2(5):64-9. https://doi. org/10.15406/jdc.2018.02.00087

16. Noronha TM, Tophakhane RS, Nadiger S. Clinicomicrobiological study of dermatophytosis in a tertiary-care hospital in North Karnataka. Indian dermatology online journal. 2016 Jul;7(4):264. https://doi.org/10.4103/2229-5178.185488

17. Ghosh RR, Ray R, Ghosh TK, Ghosh AP. Clinicomycological profile of dermatophytosis in a tertiary care hospital in West Bengal, an Indian scenario. Int J Curr Microbiol Appl Sci. 2014;3:6556 .

18. Mishra N, Rastogi MK, Gahalaut P, Yadav S, Srivastava N, Aggarwal A. Clinicomycological study of dermatophytoses in children: Presenting at a tertiary care center. Indian J Paediatr Dermatol. 2018 Oct 1;19(4):326. https://doi.org/10.4103/ ijpd.IJPD_98_17

19. Nenoff P, Verma SB, Vasani R, Burmester A, Hipler UC, Wittig F, Krüger C, Nenoff K, Wiegand C, Saraswat A, Madhu R. The current Indian epidemic of superficial dermatophytosis due to Trichophyton mentagrophytes-A molecular study. Mycoses. 2019 Apr;62(4):336-56. https:// doi.org/10.1111/myc.12878

20. Singh $S$, Verma $P$, Chandra U, Tiwary NK. Risk factors for chronic and chronic-relapsing tinea corporis, tinea cruris and tinea faciei: Results of 
a case-control study. Indian J Dermatol Venereol Leprol. 2019 Mar 1;85(2):197-200. https://doi. org/10.4103/ijdvl.IJDVL_807_17

21. Tuknayat A, Bhalla M, Kaur A, Garg S. Familial Dermatophytosis in India: A Study of the Possible Contributing Risk Factors. J Clin Aesthet Dermatol. 2020 Feb;13(2):58.

22. Neha Sharma, Uma Tendolkar. Modifiable risk factors associated with patients of tinea corporis Medpulse International Medical Journal. February 2017; 4(2):165-9.
23. Siddappa K, Mahipal OA. Dermatophytoses in Davangere. Indian J Dermatol Venereol Leprol. 1982 Sep 1;48(5):254-9.

24. Bindu V, Pavithran K. Clinico-mycological study of dermatophytosis in Calicut. Indian J Dermatol Venereol Leprol. 2002 Sep 1;68(5):259-61.

25. Yadav P, Singal A, Pandhi D, Das S. Comparative efficacy of continuous and pulse dose terbinafine regimes in toenail dermatophytosis: A randomized double-blind trial. Indian J Dermatol Venereol Leprol. 2015 Jul 1;81(4):363. https:// doi.org/10.4103/0378-6323.158634 